\title{
Short-term effects of nasal proportional assist ventilation in patients with chronic hypercapnic respiratory insufficiency
}

\author{
N. Ambrosino*, M. Vitacca*, G. Polese**, M. Pagani*, K. Foglio*, A. Rossi ${ }^{+}$
}

Short-term effects of nasal proportional assist ventilation in patients with chronic hypercapnic respiratory insufficiency. N. Ambrosino, M. Vitacca, G. Polese, M. Pagani, K. Foglio, A. Rossi. @ERS Journals Ltd 1997.

ABSTRACT: Proportional assist ventilation (PAV) has recently been proposed as a mode of synchronized partial ventilatory support. This study evaluates the short-term effects of nasal PAV on arterial blood gases in stable patients with chronic hypercapnia.

Forty two patients (30 with chronic obstructive pulmonary disease (COPD) and 12 with restrictive chest wall disease (RCWD) due to kyphoscoliosis) underwent a 1 h run of nasal PAV. Randomly, two levels of assistance were performed: 1) PAV was set at a level corresponding to volume assist (VA) and flow assist (FA) at $80 \%$ of the individual values of elastance $(E \mathrm{rs})$ and resistance $(R \mathrm{rs})$ obtained with the "runaway" method; and 2) VA and FA were set at a value corresponding to the difference between the patients' individual $E_{\mathrm{rs}}$ and $R$ rs and normal values of $E$ rs and $R$ rs. Arterial blood gases and dyspnoea (by visual analogue scale (VAS)) were evaluated in all patients during unsupported ventilation and $60 \mathrm{~min}$ of PAV.

PAV was well tolerated and resulted in significant improvement in arterial oxygen tension $\left(\mathrm{Pa}_{\mathrm{a}} \mathrm{O}_{2}\right)$, arterial carbon dioxide tension $\left(\mathrm{Pa}_{\mathrm{a}}, \mathrm{CO}_{2}\right)(6.8 \pm 0.8$ to $7.4 \pm 1.4$ and $7.2 \pm 0.9$ to $6.8 \pm 0.9 \mathrm{kPa}$, respectively) and VAS $(29 \pm 23$ to $20 \pm 18 \%)$. The effects of PAV were not different in the two groups of diseases nor in the two groups of settings.

Different settings of nasal proportional assist ventilation are well tolerated and may improve gas exchange and dyspnoea in patients with stable hypercapnic respiratory insufficiency.

Eur Respir J 1997; 10: 2829-2834.
*Salvatore Maugeri Foundation IRCCS, Lung Function Unit, Medical Centre of Gussago, ${ }^{+}$Respiratory Division and $* * \mathrm{Cy}-$ stic Fibrosis Regional Center, Ospedale Maggiore di Borgo Trento, Azienda Ospedaliera di Verona, Italy.

Correspondence: N. Ambrosino

Fondazione Salvatore Maugeri IRCCS

Pulmonary Dept

Medical Centre of Gussago

I-25064 Gussago (BS)

Italy

Keywords: Chest wall disease

chronic obstructive pulmonary disease

mechanical ventilation

respiratory muscles

Received: May 261997

Accepted after revision September 301997

This study was partially supported by Telethon, Grant no. 407, Rome, Italy, and by Respironics Inc, Murrysville, PA, USA.
The objectives of mechanical ventilation (MV) in acute respiratory failure are considered to be: to improve pulmonary gas exchange; to increase lung volume; and to unload the ventilatory muscles $[1,2]$. Noninvasive positive pressure ventilation (NPPV) has been used with these objectives also in the treatment of chronic respiratory insufficiency resulting from neuromuscular, restrictive chest wall diseases (RCWD) and chronic obstructive pulmonary diseases (COPD). It is usually delivered by either standard volume-cycled ventilators in assisted/controlled mode or by pressure support ventilation (PSV) [3-6].

Proportional assist ventilation (PAV) has recently been proposed as a mode of synchronized partial ventilatory support in which the ventilator pressure output is proportional to instantaneous patient effort. Therefore, in this mode there is automatic synchrony between the end of the patient's effort and the ventilator cycle. Furthermore, since with PAV the level of pressure delivered to the patient increases and decreases as the patient's demand increases and decreases, the responsibility for the level and pattern of ventilatory assistance depends entirely on the patient.

A few short-term studies in acutely ill patients have shown that PAV applied noninvasively is able to im- prove arterial blood gases and to unload the inspiratory muscles
[7-14]. By contrast, the effects of PAV in chronic respiratory insufficiency have not previously been reported, although it is potentially attractive to match ventilation with the spontaneously varying breathing pattern of patients in stable conditions.

This short-term study was therefore undertaken in stable hypercapnic patients with the primary goal to evaluate: 1) patients' tolerance; and 2) the effects of PAV applied noninvasively on arterial blood gases. Evaluation of the effects of PAV on dyspnoea was a secondary goal of the study.

\section{Materials and methods}

The study was approved by the Ethics Committees of Medical Centre of Gussago, S. Maugeri Foundation, and Azienda Ospedaliera of Verona. The study was conducted according to the Declaration of Helsinki. Patients gave their informed consent to participate in the study.

\section{Patients}

Forty two consecutive patients in stable conditions with chronic hypercapnia were recruited at the two institutions during the period between April 1 and October 31, 1996. 
Table 1. - Demographic, anthropometric and functional characteristics of patients

\begin{tabular}{lccc}
\hline & All patients & COPD & RCWD \\
\hline Patients n & 42 & 30 & 12 \\
Age yrs & $64 \pm 9$ & $66 \pm 7$ & $58 \pm 11$ \\
Females n & 9 & 5 & 4 \\
Height cm & $164 \pm 9$ & $166 \pm 7$ & $156 \pm 12$ \\
Weight kg & $73 \pm 16$ & $77 \pm 12$ & $61 \pm 20$ \\
FEV $1 \%$ pred & $34 \pm 15$ & $35 \pm 17$ & $32 \pm 8$ \\
FVC \% pred & $51 \pm 20$ & $56 \pm 21$ & $37 \pm 9$ \\
FEV $1 /$ FVC \% & $53 \pm 19$ & $47 \pm 16$ & $71 \pm 18$ \\
FRC \% pred & $122 \pm 9$ & $148 \pm 41$ & $58 \pm 21$ \\
TLC \% pred & $93 \pm 6$ & $110 \pm 28$ & $50 \pm 18$ \\
$P \mathrm{a}, \mathrm{O}_{2} \mathrm{kPa}$ & $6.8 \pm 0.9$ & $6.8 \pm 0.7$ & $6.7 \pm 0.8$ \\
$P \mathrm{a}, \mathrm{CO}_{2} \mathrm{kPa}$ & $7.2 \pm 0.9$ & $6.9 \pm 0.9$ & $7.8 \pm 0.6$ \\
$\mathrm{pH}$ & $7.39 \pm 0.03$ & $7.37 \pm 0.02$ & $7.38 \pm 0.03$ \\
\hline
\end{tabular}

Results are absolute values or mean $\pm S D$. COPD: chronic obstructive pulmonary disease; RCWD: restrictive chest wall disease; FVC: forced vital capacity; FEV1: forced expiratory volume in one second; FRC: functional residual capacity; TLC: total lung capacity; $\mathrm{P}_{\mathrm{a}} \mathrm{O}_{2}$ : arterial oxygen tension; $\mathrm{Pa}_{\mathrm{a}} \mathrm{CO}_{2}$ : arterial carbon dioxide tension; $\%$ pred: percentage of predicted value.

This period of the year was chosen because of the lower incidence of exacerbations. Chronic $\mathrm{CO}_{2}$ retention was due to advanced COPD in 30 patients and to RCWD, i.e. kyphoscoliosis, in 12 patients. Diagnosis of COPD was made according to the criteria of the American Thoracic Society (ATS) [15]. Demographic, anthropometric and functional characteristics of the patients are shown in table 1.

Patients with other organ failure, cancer or inability to co-operate were excluded from the study. At the time of the study the patients had to be free from exacerbations. All of the patients were using long-term oxygen therapy but no patient was receiving long-term domiciliary NPPV, although 10 patients had experienced NPPV before the study. All of the patients with COPD were receiving inhaled bronchodilators. No change in medical or oxygen therapy was made during the week preceding the study.

\section{Measurements}

Respiratory function at the time of inclusion in the study is summarized in table 1 . Lung volumes and forced vital capacity (FVC) were measured by means of a constant volume body plethysmograph (1085 Medical Graphics, St Paul, MN, USA) and spirometric values (forced expiratory volume in one second (FEV1), FVC) using a Collins 13 L type spirometer (Biomedin, Padova, Italy). The predicted values of QuANJER [16] were used. Arterial oxygen tension $\left(\mathrm{Pa}_{\mathrm{a}} \mathrm{O}_{2}\right)$, arterial carbon dioxide tension $\left(\mathrm{Pa}_{\mathrm{a}} \mathrm{CO}_{2}\right)$, arterial oxygen saturation $\left(\mathrm{Sa}_{\mathrm{a}} \mathrm{O}_{2}\right)$ and $\mathrm{pH}$ were measured by means of an automated analyser (ABL 500, Radiometer, Copenhagen, Denmark) while patients in the sitting position were breathing room air for at least $1 \mathrm{~h}$. During the study, arterial blood gases were sampled at the radial artery and measured under different conditions as previously described. Subjective rating of dyspnoea was obtained by means of a visual analogue scale (VAS) [17].

\section{Setting of PAV}

PAV was delivered through a commercial nasal mask (Respironics, Murrysville, PA, USA) by means of a prototype portable ventilator able to compensate for leaks (Respironics, Murrysville, PA, USA). A complete description of PAV can be found elsewhere and goes beyond the purposes of this study [9]. Briefly, adjustment of PAV entails levels for volume-related assist (VA) and flow-related assist (FA) according to the equation of motion:

$$
P \text { appl }=P_{0}+(V \times E \mathrm{rs})+\left(V^{\prime} \times R \mathrm{rs}\right)
$$

where: $P$ appl is the pressure applied to inflate the respiratory system either by the patient's contracting inspiratory muscles or by the ventilator or by the combination of both; $P 0$ is the elastic recoil pressure of the respiratory system at the end of expiration, which is zero if lung inflation starts from the elastic equilibrium volume of the system; $V$ and $V^{\prime}$ are the inspired volume and flow, respectively; $E_{\mathrm{rs}}$ is the total respiratory system static elastance; and $R \mathrm{rs}$ is total flow resistance.

Therefore, ideally, Ers and Rrs should be known in order to set PAV appropriately. Since measurements of $E$ rs and $R$ rs are not performed routinely in patients, they had to be done at the time of the study. To estimate Ers and $R$ rs we used the "runaway" method as described by Younes and coworkers [7-9]. "Runaway" describes a condition when the pressure applied by the ventilator exceeds the opposing elatic and resistive pressure at the end of patient inspiration. Under those circumstances flow and volume are delivered by the ventilator also during the patient's neural expiration and airway pressure continues to increase during expiration [7-9]. The "runaway" phenomenon was observed on the display of the ventilator which provides continuous recording of flow, volume and airway pressure.

Ers and Rrs were obtained using the internal measuring devices of the Respironics prototype ventilator with the patient in the semirecumbent position (see procedure below). To estimate Ers, FA was set to $1 \mathrm{cmH}_{2} \mathrm{O} \cdot \mathrm{L}^{-1} \cdot \mathrm{s}$ whereas VA was set at $2 \mathrm{cmH}_{2} \mathrm{O} \cdot \mathrm{L}^{-1}$, then VA was raised by steps of $2 \mathrm{cmH}_{2} \mathrm{O}$ until the "runaway" phenomenon occurred. The patient's Ers was assumed to be the "runaway" value minus $1 \mathrm{cmH}_{2} \mathrm{O} \cdot \mathrm{L}^{-1}$. Likewise, $R \mathrm{rs}$ was estimated by setting VA and FA at $2 \mathrm{cmH}_{2} \mathrm{O} \cdot \mathrm{L}^{-1}$ and $1 \mathrm{cmH}_{2} \mathrm{O} \cdot \mathrm{L}^{-1} \cdot \mathrm{s}$, respectively, then FA was raised by steps of $1 \mathrm{cmH}_{2} \mathrm{O} \cdot \mathrm{L}^{-1} \cdot \mathrm{s}$ until the "runaway" phenomenon occurred. Again the value of the FA at the "runaway" minus $1 \mathrm{cmH}_{2} \mathrm{O} \cdot \mathrm{L}^{-1}$.s was assumed to reflect patient's flow resistance. Therefore, for each patient individual values of $E$ rs and $R$ rs were obtained before setting PAV. Two settings of PAV were studied in this protocol: 1) PAV was set at a level corresponding to VA and FA at $80 \%$ of the individual values of $E$ rs and $R$ rs obtained with the "runaway" method (Setting 1); and VA and FA were set at a value corresponding to the difference between the patient's individual $E$ rs and $R$ rs ob-tained from the "runaway" method and values of $E$ rs of $8 \mathrm{cmH}_{2} \mathrm{O} \cdot \mathrm{L}^{-1}$ and of $R$ rs of $2 \mathrm{cmH}_{2} \mathrm{O} \cdot \mathrm{L}^{-1}$.s, which are gene-rally accepted as the values in normal subjects (Setting 2). In this way, the ventilator was presumed to cope with the additional respiratory impedance associated with the patient's condition. 
The breathing pattern, namely tidal volume $(V \mathrm{~T})$, respiratory frequency $(f \mathrm{R})$, duty cycle (inspiratory time to total breathing duration ratio $(t \mathrm{I} / \mathrm{ttot}))$, minute ventilation $\left(V^{\prime} \mathrm{E}\right.$ : $V \mathrm{~T} \times f \mathrm{R})$ and mean inspiratory flow $(V \mathrm{~T} / t \mathrm{I})$ were obtained from the ventilator signals. Each time 10 consecutive breaths were analysed and mean values were used for the subsequent analysis.

\section{Study protocol}

In the semirecumbent position, the patient initially not connected to the ventilator, breathed through the nose mask. After $20 \mathrm{~min}$ of unsupported breathing, arterial blood was sampled from the radial artery. Then, according to a randomized order, either Setting 1 or Setting 2 of PAV was applied by the ventilator and the patient was ventilated with the assigned setting for $1 \mathrm{~h}$ in the semirecumbent position. An appropriately sized commercial nose mask (Respironics, Murrysville, PA, USA) was sel-ected for each patient. Special care was taken to ensure mouth closure throughout the procedure. A nurse not involved in the procedure was always present for patient care. The ventilator circuit was equipped with the Sanders NRV-2 valve (Respironics, Murrysville, $\mathrm{PA}, \mathrm{USA}$ ) to prevent $\mathrm{CO}_{2}$ rebreathing [18]. After $60 \mathrm{~min}$, with the patient still connected to the PAV ventilator, arterial blood was sampled again from the radial artery of the other arm.

In 27 patients (five females, aged 65 49 yrs, 22 COPD, 5 RCWD), VAS was measured before and at the 60th minute of PAV ventilation. The same measurement was obtained in 10 additional control patients (six COPD, four RCWD, aged $65 \pm 10$ yrs, weight $65 \pm 20 \mathrm{~kg}$ ) undergoing $1 \mathrm{~h}$ of nasal continuous positive airway pressure (CPAP) $2 \mathrm{cmH}_{2} \mathrm{O}$ delivered by the same ventilator.

\section{Statistical analysis}

All data are reported as mean \pm SD. The significance of differences between control and PAV values within groups was analysed by paired t-test. Differences between groups were analysed by unpaired t-test. A p-value of less than 0.05 was considered to be statistically significant.

\section{Results}

All patients tolerated PAV very well. Neither discomfort nor adverse effects were observed throughout the study. No apnoea periods, and no "runaway" due either to overassistance or to sudden changes in patient's respiratory mechanics, occurred during the trials.
Table 2. - Characteristics of patients studied with each level of support

\begin{tabular}{lcc}
\hline & Setting 1 & Setting 2 \\
\hline Patients n & 20 & 22 \\
Age yrs & $66 \pm 7$ & $62 \pm 1$ \\
Females n & 4 & 5 \\
Height cm & $166 \pm 8$ & $161 \pm 10$ \\
Weight kg & $73 \pm 16$ & $73 \pm 16$ \\
$\mathrm{COPD} \mathrm{n}$ & 15 & 15 \\
$\mathrm{RCWD} \mathrm{n}$ & 5 & 7 \\
$P \mathrm{a}, \mathrm{O}_{2} \mathrm{kPa}$ & $6.7 \pm 0.9$ & $6.8 \pm 0.9$ \\
$P \mathrm{a}, \mathrm{CO}_{2} \mathrm{kPa}$ & $7.4 \pm 0.8$ & $7.1 \pm 1.0$ \\
$\mathrm{pH}$ & $7.39 \pm 0.03$ & $7.38 \pm 0.03$ \\
$\mathrm{VA} \mathrm{cmH}$ & $16.7 \pm 5.9$ & $10.7 \pm 5.7$ \\
$\mathrm{FA} \mathrm{cmH}_{2} \mathrm{O} \cdot \mathrm{L}^{-1} \cdot \mathrm{s}$ & $4.1 \pm 1.3$ & $3.8 \pm 0.9$ \\
\hline
\end{tabular}

Results are mean $\pm S D$. VA: volume assist; FA: flow assist. For further definitions, see legend to table 1 .

Table 3. - Levels of respiratory elastance and resistance in relation to diagnosis and level of support

\begin{tabular}{|c|c|c|c|c|c|}
\hline & $\begin{array}{c}\text { All } \\
\text { patients }\end{array}$ & COPD & RCWD & Setting 1 & Setting 2 \\
\hline $\begin{array}{l}E_{\mathrm{rs}} \\
\mathrm{cmH}{ }_{2} \mathrm{O} \cdot \mathrm{L}^{-1}\end{array}$ & $19.7 \pm 6.5$ & $17.9 \pm 7.5$ & $24.2 \pm 8.2$ & $18.7 \pm 5.7$ & $20.9 \pm 7.4$ \\
\hline $\begin{array}{l}R \mathrm{rs} \\
\mathrm{cmH}_{2} \mathrm{O} \cdot \mathrm{L}^{-1} \cdot \mathrm{s}\end{array}$ & $5.5 \pm 1.3$ & $5.5 \pm 1.4$ & $5.3 \pm 1.2$ & $5.8 \pm 0.9$ & $5.1 \pm 1.7$ \\
\hline
\end{tabular}

Results are mean \pm S . Ers: total respiratory system elastance; $R$ rs: respiratory flow resistance. For further definitions, see legend to table 1.

Table 2 shows the characteristics of the two groups of patients separated according to the settings of PAV. There were no significant differences between the two groups in anthropometric features, diagnosis or baseline arterial blood gases. Clearly, the levels of VA and FA support were different as defined by the protocol. Table 3 shows the mean values of $E$ rs and $R$ rs measured by means of the "runaway" method in all 42 patients, as well as in the patients classified by diagnosis and PAV settings. Ers was higher in RCWD compared to COPD patients, whereas Rrs was similar in the two groups and slightly greater than normal.

Table 4 shows the effects of PAV on mean values of arterial blood gases in all patients and according to the PAV settings. In all groups of settings and diagnosis, PAV resulted in improvements in $\mathrm{Pa}, \mathrm{O}_{2}$ and $\mathrm{Pa}, \mathrm{CO}_{2}$. Figure 1 shows the PAV-induced mean and individual changes in $P \mathrm{a}, \mathrm{O}_{2}$ and $\mathrm{Pa}, \mathrm{CO}_{2}$ according to the underlying disease. The regression analysis for the whole patient group indicates a slight but significant correlation $(\mathrm{r}=0.38, \mathrm{p}=0.012)$ between PAV-induced changes in $\mathrm{Pa}, \mathrm{CO}_{2}$ and baseline values of $\mathrm{Pa}_{1} \mathrm{CO}_{2}$. Figure 2 shows the correlation between the $\mathrm{PAV}$-induced changes in $\mathrm{Pa}, \mathrm{O}_{2}$ and $\mathrm{Pa}, \mathrm{CO}_{2}$.

Table 4. - Changes in arterial blood gases during different settings of PAV

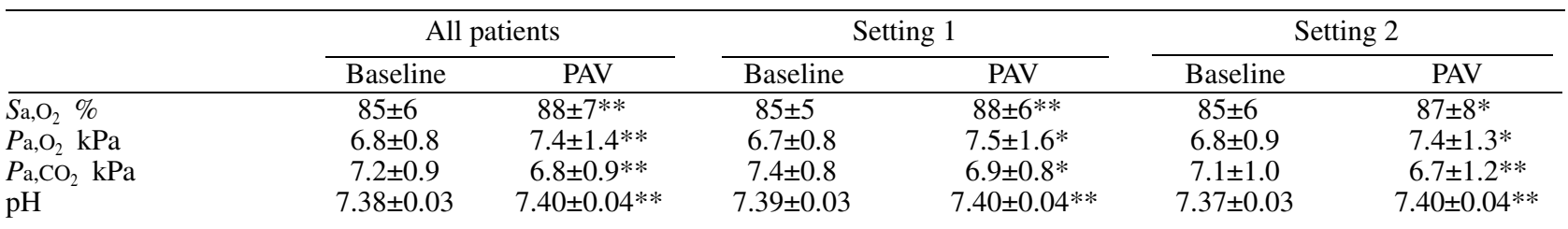

Results are mean \pm D D . *:p<0.05; **: $\mathrm{p}<0.01$. PAV: proportional assist ventilation; $\mathrm{Sa}_{\mathrm{a}} \mathrm{O}_{2}$ : arterial oxygen saturation; $P \mathrm{a}, \mathrm{O}_{2}$ : arterial oxygen tension; $P \mathrm{a}, \mathrm{CO}_{2}$ : arterial carbon dioxide tension. 


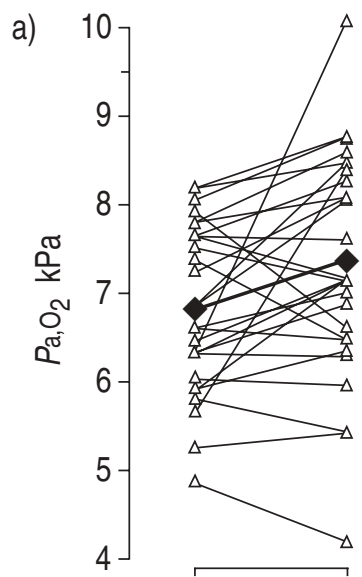

b)

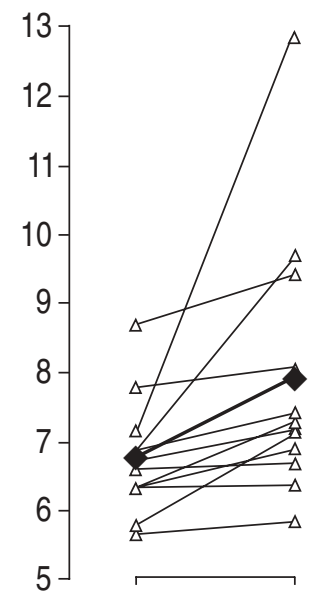

c)

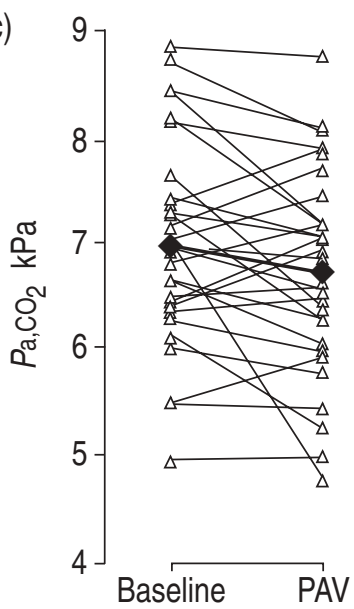

d)

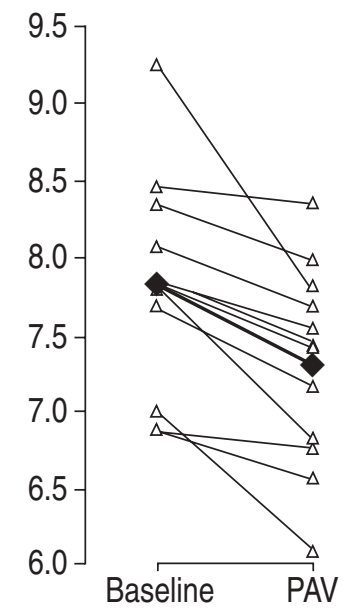

Fig. 1. - Mean (- - ) and individual $\left(-{ }_{\Delta}-\right)$ changes in $P_{\mathrm{a}, \mathrm{O}_{2}}(\mathrm{a}, \mathrm{b})$ and $P_{\mathrm{a}}, \mathrm{CO}_{2}(\mathrm{c}, \mathrm{d})$ in $\mathrm{COPD}(\mathrm{a}, \mathrm{c})$ and $\mathrm{RCWD}(\mathrm{b}, \mathrm{d})$ patients. Differences between baseline and proportional assist ventilation (PAV) were significant $(\mathrm{p}<0.05)$. For definitions see legend to table 1 .

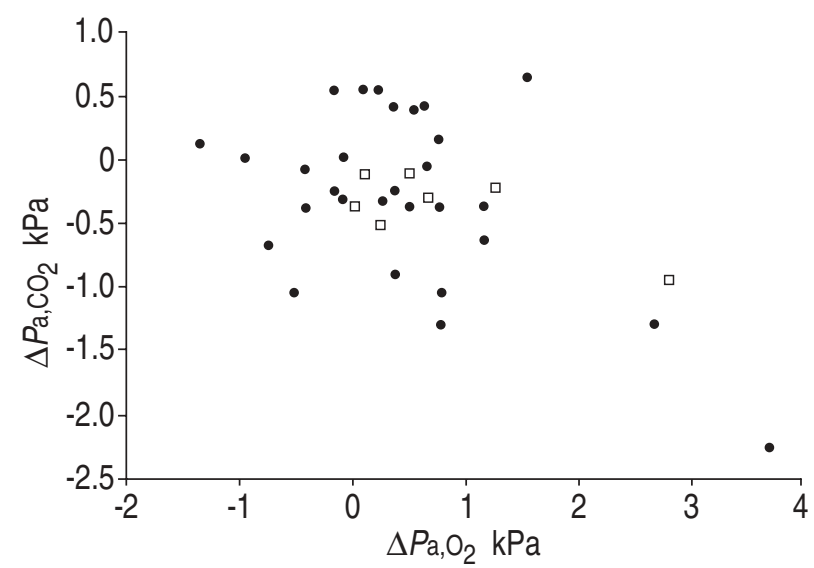

Fig. 2. - Individual changes $(\Delta)$ in $P_{\mathrm{a}}, \mathrm{CO}_{2}$ and $P \mathrm{a}, \mathrm{O}_{2}$ in $\mathrm{COPD}(\bullet)$ and RCWD ( $\square$ ) patients. For definitions see legend to table 1.

The effect of PAV on breathing pattern is shown in figure 3. PAV resulted in a significant increase in $V \mathrm{~T}$ and a significant reduction in $t \mathrm{I} / t$ tot; $V^{\prime} \mathrm{E}$ and $f \mathrm{R}$ did not change significantly.

VAS improved significantly with a PAV in the patients assessed $(29 \pm 23$ to $20 \pm 18 \%$; $\mathrm{p}<0.05)$ but not in 10 control patients.

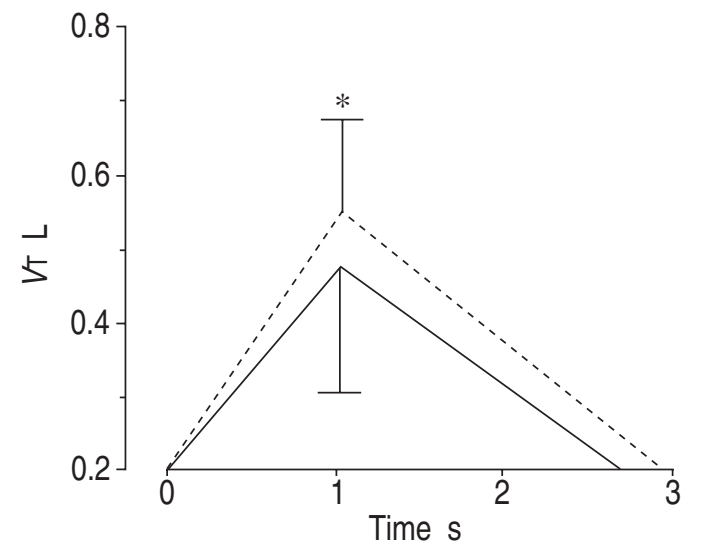

Fig. 3. - Breathing pattern of the whole population during unsupported (-) and proportional assist (- -) ventilation (mean \pm SD). *: $\mathrm{p}<0.05$.

\section{Discussion}

To our knowledge, this is the first study performed in stable patients with chronic hypercapnia to assess the impact of a patient-guided mechanical ventilatory pattern on arterial blood gases. These findings show that the patient-guided mechanical ventilatory pattern did not result in derangement in gas exchange; by contrast, we have shown that $1 \mathrm{~h}$ of PAV caused a significant improvement in arterial blood gases, Furthermore, short-term administration of PAV was well tolerated in all patients and was able to improve dyspnoea. This short-term study suggests that PAV may be of some clinical utility in patients with chronic respiratory insufficiency.

Our patients suffered from chronic hypercapnic respiratory insufficiency. Their Ers and Rrs were estimated by means of the "runaway" technique. It is interesting to note that whereas Ers was higher in RCWD compared to COPD patients, Rrs was similar in the two groups and slightly greater than normal (table 3). In patients with kyphoscoliosis, the high $E$ rs reflects increased chest wall stiffness while Rrs is increased due to the abnormally low FRC as report-ed in table $1[19,20]$. Values of $R$ rs in our COPD pati- ents may appear lower than expected in view of the low FEV1 reported in table 1. However, it has been shown that the site of obstruction in COPD is located in small airways, whose resistance has little impact on $R$ rs which is mainly determined by changes in central airway calibre [21]. In addition, the reduction in maximal expiratory flows in COPD is due also to decreased lung elastic recoil and expiratory flow limitation [22]. Furthermore, our COPD patients were in a stable condition, with no recent exacerbation and hence excessive abnormality of Rrs would not be expected. However we are clearly aware of the limitations of these measurements and of the fact that measurements of Ers and Rrs obtained by means of the "runaway" technique need further validation.

All patients tolerated PAV very well. For the setting examined, no "runaway" due either to overassistance or to sudden changes in patient's respiratory mechanics occurred during the trials. Furthermore, the presence of leaks in the patient-ventilator ensemble was carefully checked in each trial and no "runaway" due to leaks was observed. However, this might be due to the short duration of the study, and "runaway" due to leaks over longer periods of PAV application, as well changes in respiration mechanics 
in relatively long-term studies, cannot be excluded on the basis of our results. Furthermore, leak is a common problem during sleep and "runaway" due to leaks might cause significant sleep disruption which would limit the usefulness of PAV during sleep. Therefore, before PAV can be recommended for domiciliary use, effectiveness during sleep needs to be demonstrated.

PAV resulted in significantly improved arterial blood gases, irrespective of diagnosis and settings. $P \mathrm{a}, \mathrm{O}_{2}$ improved and because the values were on the steep portion of the haemoglobin-oxygen $\left(\mathrm{HbO}_{2}\right)$ dissociation curve, $\mathrm{Sa}, \mathrm{O}_{2}$ also improved. $\mathrm{Pa}_{1} \mathrm{CO}_{2}$ decreased and $\mathrm{pH}$ increased, though the latter remained in the normal predicted range for patients with chronic stable disease. It is noteworthy that, as reported with other modalities of mechanical ventilation $[23,24]$, the decrease in $\mathrm{Pa}_{\mathrm{a}} \mathrm{CO}_{2}$, although significant, was small both on average and in individuals. In the chronic condition, a rapid and marked reduction in $\mathrm{CO}_{2}$ is generally not advisable. In fact, excessive reduction in $\mathrm{Pa}_{\mathrm{a}} \mathrm{CO}_{2}$ could result in less inspiratory effort and hence reduce $V \mathrm{~T}$, a phenomenon which was not observed in the present study.

A possible explanation of the changes in arterial blood gases may be found in an increase in alveolar ventilation, as suggested by the changes in breathing pattern during PAV (fig. 3). In this respect it should be noticed that the smaller $t \mathrm{t} / t$ tot ratio at the same $f \mathrm{R}$ allows a slightly longer expiratory time which favours lung emptying [25] and respiratory muscle rest [26].

The improvements in arterial blood gases were significant in both COPD and RCWD groups (fig. 1). However, the increase in $\mathrm{Pa}, \mathrm{O}_{2}$ and the decrease in $P \mathrm{a}, \mathrm{CO}_{2}$ were slightly greater in patients with chronic respiratory insufficiency due to RCWD than to COPD. Whether this finding reflects a characteristic of the population under study or whether it indicates a truly better response to PAV in patients with RCWD remains to be investigated in a larger population.

In this study, different levels of support resulted in similar effects, indicating that even a low level of support may be enough to improve arterial blood gases and dyspnoea. A level of PAV setting corresponding to VA and FA at $80 \%$ of the individual values of Ers and Rrs (Setting 1) was chosen to obtain the greatest unloading of respiratory muscles. The value of VA and FA corresponding to the difference between the patient's individual $E$ rs and $R$ rs and values of $E_{\mathrm{rs}}$ and $R$ rs generally accepted as normal (Setting 2) was chosen to reduce the excess load on the respiratory muscles. No difference was found between the two settings of $\mathrm{PAV}$, although Setting 2 gave a VA $\sim 6 \mathrm{cmH}_{2} \mathrm{O} \cdot \mathrm{L}^{-1}$ lower than Setting 1.

With NPPV, a reduced level of support may be useful to increase patient tolerability, reducing air leaks and sideeffects $[8,9]$. One of the potential benefits of noninvasive PAV may well be the lower levels of airway pressure necessary to improve oxygen delivery, thus also reducing the haemodynamic effects [11]. Indeed, in stable COPD, reductions in cardiac output and oxygen delivery have been observed with noninvasive PSV [27]. On the other hand, in intubated patients with acute respiratory failure, both RANIERI et al. [10] and NAVALESI et al. [12] found that increasing the level of support produced a greater ventilatory effect and a greater reduction in inspiratory effort.
Whether this reflects a difference between acute and chronic patients remains to be established.

Although not observed in 10 control patients receiving "sham" ventilation with CPAP $2 \mathrm{cmH}_{2} \mathrm{O}$, the apparent changes in dyspnoea must be considered cautiously as the control patients were not randomly assigned, nor were they matched with the population under study. Nevertheless, it is unlikely that improvements in dyspnoea were influenced by a "placebo" effect. A placebo effect should have been excluded as both modalities of ventilation were performed by means of the same ventilator. Therefore, with this limitation these results suggest an effect on dyspnoea. It has been shown that PAV is able to unload the respiratory muscles [7-9] which may explain the effects on dyspnoea. Furthermore, at least in acute respiratory failure there is evidence that with the same level of respiratory muscle unloading PAV seems more effective in reducing dyspnoea than PSV [10].

This was a short-term study and its conclusions need to be confirmed by long-term studies. Nevertheless, shortterm studies are required before longer term investigation of therapeutic interventions in order to show, at least, the tolerance of the patients to the treatment.

In conclusion, in a short-term study, in stable patients with chronic hypoxaemic and hypercapnic respiratory insufficiency due to chronic obstructive pulmonary disease or restrictive chest wall disease (kyphoscoliosis), proportional assist ventilation delivered by a nose mask was well tolerated and improved arterial blood gases with different settings. An increase in alveolar ventilation, as suggested by the modifications of breathing pattern, was likely to be the major mechanism through which proportional assist ventilation improved the arterial blood gases.

\section{References}

1. Slutsky AS. Mechanical ventilation. Chest 1993; 104: 1833-1859.

2. $\quad$ Tobin MJ. Mechanical ventilation. N Engl J Med 1994; 330: 1056-1061.

3. Meyer TJ, Hill NS. Noninvasive positive pressure ventilation to treat respiratory failure. Ann Intern Med 1994; 120: 760-770.

4. Ambrosino N, Nava S, Bertone P, Fracchia C, Rampulla C. Physiologic evaluation of pressure support ventilation by nasal mask in patients with stable COPD. Chest 1992; 101: 385-391.

5. Simonds AK, Elliott MW. Outcome of domiciliary nasal intermittent positive pressure ventilation in restrictive and obstructive disorders. Thorax 1995; 50: 604-609.

6. Meecham Jones DJ, Paul EA, Jones PW, Wedzicha JA. Nasal pressure support ventilation plus oxygen compared with oxygen therapy alone in hypercapnic COPD. Am J Respir Crit Care Med 1995; 152: 538-544.

7. Younes M. Proportional assist ventilation, a new approach to ventilatory support: theory. Am Rev Respir Dis 1992; 145: 114-120.

8. Younes M, Puddy A, Roberts D, et al. Proportional assist ventilation: results of an initial clinical trial. Am Rev Respir Dis 1992; 145: 121-125.

9. Younes M. Proportional assist ventilation. In: Tobin MJ, ed. Principles and Practice of Mechanical Ventilation. New York, McGraw-Hill inc, 1994; pp. 349-370. 
10. Ranieri MV, Giuliani R, Mascia L, et al. Patient-ventilator interaction during acute hypercapnia: pressure-support vs proportional-assist ventilation. J Appl Physiol 1996; 81: 426-436.

11. Patrick W, Webster K, Ludwig L, Roberts D, Wiebe P, Younes M. Noninvasive positive-pressure ventilation in acute respiratory distress without prior chronic respiratory failure. Am J Respir Crit Care Med 1996; 153: 10051011.

12. Navalesi P, Hernandez P, Wongsa A, Laporta D, Goldberg P, Gottfried SB. Proportional assist ventilation in acute respiratory failure: effects on breathing pattern and inspiratory effort. Am J Respir Crit Care Med 1996; 154: $1330-1338$.

13. Marantz S, Patrick W, Webster K, Roberts D, Oppenheimer D, Younes M. Responses of ventilator dependent patients to different levels of proportional assist. J Appl Physiol 1996; 80: 397-403.

14. Ranieri MV, Grasso S, Mascia L, et al. Effects of proportional assist ventilation on inspiratory muscle effort in patients with chronic obstructive pulmonary disease and acute respiratory failure. Anesthesiology 1997; 86: 79-91.

15. American Thoracic Society. Standards for the diagnosis and care of patients with chronic obstructive pulmonary disease (COPD) and asthma. Am Rev Respir Dis 1987; 136: 225-243.

16. Quanjer PH. Working Party on "Standardization of lung function tests". Bull Eur Physiopathol Respir 1983; 19 (Suppl. 5): 7-10.

17. Aitken RCB. Measurement of feelings using visual analogue scales. Proc R Soc Med 1969; 62: 989-993.

18. Ferguson T, Gilmartin M. $\mathrm{CO}_{2}$ rebreathing during BiPAP ventilatory assistance. Am J Respir Crit Care Med 1995; 151: 1126-1135.
19. Eveloff SE, McCool FD. Disorders of the chest wall: implications for respiratory failure. In: Marini JJ, Roussos C, eds. Ventilatory Failure. Berlin, Springer Verlag, 1991; 15: pp. 219-239.

20. Estenne M. Pathophysiology of ventilatory failure in patients with neuromyopathies. In: Marini JJ, Roussos C, eds. Ventilatory Failure. Berlin, Springer Verlag, 1991; 15: pp. 240-254.

21. Hogg JC, Macklem PT, Thurlbeck WM. Site and nature of airways obstruction in chronic obstructive lung disease. N Engl J Med 1969; 278: 1355-1360.

22. Pride NB, Milic-Emili J. Lung mechanics. In: Calverley P, Pride NB, eds. Chronic Obstructive Pulmonary Disease. London, Chapman \& Hall, 1995; pp. 135-160.

23. Restrick LJ, Fox NC, Braid G, Ward EM, Paul EA, Wedzicha JA. Comparison of nasal pressure support ventilation with nasal intermittent positive pressure ventilation in patients with nocturnal hypoventilation. Eur Respir $J$ 1993; 6: 364-370.

24. Meecham Jones DJ, Wedzicha JA. Comparison of pressure and volume preset nasal ventilator systems in stable chronic respiratory failure. Eur Respir J 1993; 6: 10601064.

25. Rossi A, Polese G, Brandi G. Dynamic hyperinflation. In: Marini JJ, Roussos C, eds. Ventilatory Failure. Berlin, Springer Verlag, 1991; 15: pp. 199-218.

26. Roussos C, Macklem PT. Inspiratory muscle fatigue. In: Macklem PT, Mead J, eds. Handbook of Physiology. Section 3. The Respiratory System. Bethesda, American Physiological Society, 1986; pp. 511-527.

27. Ambrosino N, Nava S, Torbicki A, et al. Hemodynamic effects of pressure support ventilation and PEEP by nasal route in patients with chronic hypercapnic respiratory insufficiency. Thorax 1993; 48: 523-528. 